\title{
Structural basis for the modulation of voltage-gated sodium channels by animal toxins
}

\author{
Huaizong Shen ${ }^{1,2,3 *}$, Zhangqiang $\mathrm{Li}^{1,2,3 *}$, Yan Jiang ${ }^{4 *}$, Xiaojing Pan ${ }^{1,2,3 *}$, Jianping Wu ${ }^{1,2,3}+$, \\ Ben Cristofori-Armstrong ${ }^{4}$, Jennifer J. Smith ${ }^{4}$, Yanni K. Y. Chin ${ }^{4}$, Jianlin Lei ${ }^{5}$, Qiang Zhou ${ }^{1,2,3}$, \\ Glenn F. King ${ }^{4}$, Nieng Yan ${ }^{1,2,3}+*$
}

${ }^{1}$ State Key Laboratory of Membrane Biology, School of Life Sciences and School of Medicine, Tsinghua University, Beijing 100084, China. ${ }^{2}$ Beijing Advanced Innovation Center for Structural Biology, School of Life Sciences and School of Medicine, Tsinghua University, Beijing 100084, China. ${ }^{3}$ Tsinghua-Peking Joint Center for Life Sciences, School of Life Sciences and School of Medicine, Tsinghua University, Beijing 100084, China. ${ }^{4}$ Institute for Molecular Bioscience, The University of Queensland, St. Lucia, Queensland 4072, Australia. ${ }^{5}$ Technology Center for Protein Sciences, Ministry of Education Key Laboratory of Protein Sciences, School of Life Sciences, Tsinghua University, Beijing 100084, China.

*These authors contributed equally to this work. †Present address: Department of Molecular Biology, Princeton University, Princeton, NJ 08540, USA. ¥Corresponding author. Email: nyan@princeton.edu (N.Y.); glenn.king@imb.uq.edu.au (G.F.K.); zhouq2015@mail.tsinghua.edu.cn (Q.Z.)

Animal toxins that modulate the activity of $\mathrm{Na}_{\mathrm{v}}$ channels are broadly divided into two categories-pore blockers and gating modifiers. The pore blockers tetrodotoxin (TTX) and saxitoxin (STX) are responsible for pufferfish and shellfish poisoning in humans, respectively. Here we present structures of the insect $\mathrm{Na}_{\mathrm{v}}$ channel $\mathrm{Na}_{\mathrm{v}} \mathrm{PaS}$ bound to a gating modifier toxin Dcla at $2.8 \AA$ and in the presence of TTX or STX at $2.6 \AA$ and $3.2 \AA$ resolution, respectively. Dcla inserts into the cleft between $V_{S D_{\|}}$and the pore of $\mathrm{Na}_{\mathrm{v}} \mathrm{PaS}$, making key contacts with both domains. The structures with bound TTX or STX reveal the molecular details for the specific blockade of $\mathrm{Na}^{+}$access to the selectivity filter from the extracellular side by these guanidinium toxins. The structures shed light on structure-based development of $\mathrm{Na}_{\mathrm{v}}$ channel drugs.

Voltage-gated sodium $\left(\mathrm{Na}_{\mathrm{v}}\right)$ channels play a critical role in generating membrane excitability (1), and are targeted by numerous chemical insecticides and human drugs. $\mathrm{Na}_{\mathrm{v}}$ channels are also the most common target of venom neurotoxins. $\mathrm{Na}_{\mathrm{v}}$ channels comprise one single polypeptide chain that folds to four homologous repeats (repeats I-IV), each containing six transmembrane helices designated S1-S6. The S1-S4 segments in each repeat constitute the voltage-sensing domain (VSD), and the S5, S6, and their intervening segments from the four repeats together enclose the ion-conducting pore domain.

While small-molecule neurotoxins such as tetrodotoxin (TTX) and saxitoxin (STX) function as pore blockers, the vast majority of peptidic $\mathrm{Na}_{\mathrm{v}}$ channel toxins are gating modifiers that trap the channel in a particular stage of the gating cycle through interactions with one or more VSDs (2). In contrast to pore blockers, gating modifier toxins (GMTs) have more complex allosteric effects on $\mathrm{Na}_{\mathrm{v}}$ channel function, and they can inhibit (3) or agonise (4) the channel. GMTs, which in general have greater selectivity than pore blockers, are valuable leads for the development of subtype-selective $\mathrm{Na}_{\mathrm{v}}$ channel drugs $(3,5,6)$.

Despite extensive studies of the molecular basis by which GMTs modulate $\mathrm{Na}_{\mathrm{v}}$ channel function, no consensus model has emerged of this interaction. Early studies suggested a dominant role for the extracellular S3-S4 loop in GMT binding $(7,8)$, but subsequent studies have revealed a key role for the S1-S2 loop in many GMT interactions $(4,9,10)$. More recent studies suggest that GMTs nestle into an extracellularfacing cavity between the S1-S4 helices, enabling them to act as a wedge that impedes voltage sensor movement $(5,11)$. It has been suggested that large GMTs such as those found in scorpion venom might be able to simultaneously contact the VSD and the extracellular loop connecting the pore helix P2 and the S6 segment in pore domain (12), but no studies to date have predicted a role for any of the pore-domain membrane helices in GMT binding.

Small molecules that occlude the pore of $\mathrm{Na}_{\mathrm{v}}$ channels are rare in animal venoms, but TTX and STX are exceptions. As the name indicates, TTX was originally found in tetrodontoid fish exemplified by the pufferfish (fugu). Pufferfish poisoning, resulting from consumption of TTX-containing fish, was documented thousands of years ago in China, Egypt, and later in Japan and Mexico $(13,14)$. TTX was subsequently shown to be present in venom of the deadly blue-ringed octopus, the poisonous secretions of frogs and newts, and in predatory moon snails; these animals do not synthesize TTX but rather acquire it from endosymbiotic bacteria (15). It was discovered in the mid- $20^{\text {th }}$ century that the potent toxicity of TTX is due to suppression of action potential generation through specific inhibition of $\mathrm{Na}^{+}$influx $(14,16-18)$. STX is a related guanidinium neurotoxin, produced by marine dinoflagellates and cyanobacteria, that competes with TTX for 
binding to $\mathrm{Na}_{\mathrm{v}}$ channels (15). The term saxitoxin is also used to refer to a class of $>50$ structurally related toxins that are responsible for paralytic shellfish poisoning $(19,20)$.

Owing to their stringent specificity for $\mathrm{Na}_{\mathrm{v}}$ channels, TTX and STX are widely used for pharmacological characterization of $\mathrm{Na}_{\mathrm{v}}$ channels (21-24). The nine subtypes of mammalian $\mathrm{Na}_{\mathrm{v}}$ channels are classified as TTX-resistant or TTXsensitive based on their susceptibility to TTX. The latter are inhibited by nanomolar concentrations of TTX, whereas the TTX-resistant subtypes $\mathrm{Na}_{\mathrm{v}} 1.5, \mathrm{Na}_{\mathrm{v}} 1.8$, and $\mathrm{Na}_{\mathrm{v}} 1.9$ only respond to micromolar concentrations of the toxin $(24,25)$. Despite comprehensive studies over the past six decades (2629), our molecular understanding of the mechanism of action of these toxins has been impeded by the lack of structural information. Crystal structures of several bacterial $\mathrm{Na}_{\mathrm{v}}$ channels have been elucidated (30-32), but these homotetrameric prokaryotic orthologs are insensitive to TTX/STX because they lack the receptor site found in their single-chain, asymmetric eukaryotic counterparts (33).

We recently elucidated the structure of the eukaryotic $\mathrm{Na}_{\mathrm{v}}$ channel $\mathrm{Na}_{\mathrm{v}} \mathrm{PaS}$ from American cockroach Periplaneta americana at $3.8 \AA$ A resolution (34). Here we present a $2.8 \AA$ resolution cryo-EM structure of this channel in complex with Dcla, a peptidic GMT from venom of the desert bush spider Diguetia canities that promotes channel opening of the $\mathrm{Na}_{\mathrm{v}}$ channel from German cockroach (10). We also report cryoEM structures of the $\mathrm{Na}_{\mathrm{v}} \mathrm{PaS}-\mathrm{Dcla}$ complex in the presence of the pore blockers TTX and STX at 2.6 $\AA$ and $3.2 \AA$, respectively. A $\mathrm{Na}^{+}$binding site in the selectivity filter (SF) constituted by three carboxylate groups is observed. The structures elucidate the molecular basis for pore blockade by TTX/STX.

\section{Results \\ Structural determination of $\mathrm{Na}$ PaS in complex with Dc1a, TTX, and STX}

Details of cryo-sample preparation, image acquisition, data processing, model building, and structure refinement can be found in Methods. Briefly, micrographs collected on a Titan Krios electron microscope equipped with Gatan K2 Summit detector, GIF Quantum energy filter, and spherical aberration (Cs) image corrector, were used to reconstruct a 3D EM map for the $\mathrm{Na}_{\mathrm{v}} \mathrm{PaS}$-Dcla complex purified in the presence of $300 \mathrm{mM} \mathrm{NaCl}$ to an overall resolution of 2.8 A. Following a similar protocol, the structures of $\mathrm{Na}_{\mathrm{v}} \mathrm{PaS}-\mathrm{Dcla}$ bound to TTX and STX were obtained at $2.6 \AA$ and $3.2 \AA$, respectively. The central region of $\mathrm{Na}_{\mathrm{v}} \mathrm{PaS}$ exhibits higher resolution in all three structures. Application of a mask for the central region during post-processing further improved the resolution of this region to $2.7 \AA$ for $\mathrm{Na}_{\mathrm{v}} \mathrm{PaS}-\mathrm{Dcla}$, and $3.1 \AA$ for $\mathrm{Na}_{\mathrm{v}} \mathrm{PaS}-$ Dcla-STX, while that for $\mathrm{Na}_{\mathrm{v}} \mathrm{PaS}-\mathrm{Dcla}$-TTX remained at $2.6 \AA$ (Fig. 1, A and B, figs. S1 to S4, and table S1). The excellent quality of the EM maps ensured reliable assignment of the ligands and surrounding residues. All residues of the selectivity filter (SF), including the invariant residues from the four repeats, Asp/Glu/Lys/Ala (DEKA), and surrounding segments are unambiguously resolved in the high-resolution EM reconstructions (Fig. 1C and fig. S4).

\section{$V_{S S} D_{I I}$ and the pore domain together accommodate Dc1a} The structure of the Dcla-Na ${ }_{\mathrm{v}} \mathrm{PaS}$ complex (Fig. 2, A to C) confirms that VSD $\mathrm{VII}_{\text {II }}$ constitutes the primary docking site for Dcla, as we reported previously (10). Comparison with the ligandfree $\mathrm{Na}_{\mathrm{v}} \mathrm{PaS}$ structure (34) reveals minor conformational changes in the channel upon Dcla binding, mainly affecting VSD $_{\text {II }}$ (fig. S5). In contrast, the structure of Dc1a undergoes considerable rearrangement (Fig. 2B). The NMR structure of Dcla alone contains five short $\beta$ strands that are organized into an $\mathrm{N}$-terminal $\beta$-sheet and a C-terminal inhibitor cystine knot (knottin) motif (10). In the complex, however, the two C-terminal $\beta$ strands extend into the previously unstructured connecting loop region to form an elongated $\beta$-hairpin that inserts deeply into the extracellular cavity enclosed by the four segments in $\mathrm{VSD}_{\mathrm{II}}$ and the adjacent pore-forming S5 segment from repeat III (S5 $5_{\text {III }}$ ) (Fig. 2, A and B).

Dcla makes extensive polar and hydrophobic interactions with $\mathrm{Na}_{\mathrm{v}} \mathrm{PaS}$ that are more complex than predicted by any model of GMT binding, involving interactions with the S1-S2 loop (the loop that connects S1 and S2), the gating charge on S4, the extracellular pore loops, and the S5 pore-domain helix of repeat III. The toxin makes no interactions with the S3-S4 loop. The edge of the $\beta$ sheet of Dcla interacts with the short extracellular helix in repeat III above the pore domain (designated E $\alpha \mathrm{III}$ ) (Fig. 2B); specifically Tyr33 and Asp56 on Dc1a interact with His1032 and Arg1027 on $\mathrm{Na}_{\mathrm{v}} \mathrm{PaS}$, respectively (Fig. $2 \mathrm{C}$, left). On one side of the $\mathrm{VSD}_{\text {II }}$ cavity, the toxin interacts extensively with the S1-S2 loop (designated L1-2 $2_{\text {II }}$; in particular, the guanidinium group of Dcla-Arg41 interacts with the main chain carbonyl oxygen and the side chain carboxyl group of Asp542 (Fig. 2C, middle).

The $\beta 3-\beta 4$ hairpin of Dcla inserts deep into the VSD $_{\text {II }}$ cavity, with Phe47 and Phe48 at the tip of the hairpin surrounded by hydrophobic residues from $\mathrm{S1}_{\mathrm{II}}$ and the side wall of the pore domain involving $\mathrm{S}_{\text {III. }}$. Meanwhile, the aromatic ring of Dc1a-Phe48 makes a $\pi$-cation interaction with the gating-charge residue Arg613 (R3) (Fig. 2C, right). Gln1002 on S5 III makes extensive polar interactions with the side chain of Dcla-Lys44 and the backbone amide of Dcla-Phe48. These specific interactions with both $\mathrm{VSD}_{\text {II }}$ and the pore domain collectively stabilize VSD II $_{\text {in }}$ the "up" state, consistent with Dcla inducing opening of the channel (10).

We investigated the importance of these intermolecular interactions by examining the effect of toxin and channel mutations using the orthologous $\mathrm{Na}_{\mathrm{v}} \mathrm{Bg}$ channel from the German cockroach Blattella germanica (Fig. 2, D and E). $\mathrm{Na}_{\mathrm{v}} \mathrm{Bg}$ 
is potently activated by Dcla but, unlike $\mathrm{Na}_{\mathrm{v}} \mathrm{PaS}$, it is amenable to electrophysiological analysis (10). Modulation of $\mathrm{Na}_{\mathrm{v}} \mathrm{Bg}$ activity by Dcla was almost abolished when residues Asp21, Tyr33, Arg41, Lys44, and Asp56 were mutated to Ala, while Phe47A, Phe48A, and S49A mutations severely diminished but did not completely abrogate Dcla activity (Fig. 2D and fig. S6). Based on ${ }^{1} \mathrm{H}$ NMR chemical shifts, none of these mutations perturb the structure of Dcla (figs. S7 and S8), thus we conclude that they all contribute to Dcla modulation of insect $\mathrm{Na}_{\mathrm{v}}$ channels.

Mutation of $\mathrm{Na}_{\mathrm{v}} \mathrm{Bg}$ residues involved in Dcla binding caused minor shifts in the conductance-voltage $(\mathrm{G}-\mathrm{V})$ relationship for the channel (fig. S9). Thus, for each channel mutant, we quantified the previously noted ability of Dcla to induce a hyperpolarizing shift $\left(\Delta_{\mathrm{G}-\mathrm{V}}\right)$ in the G-V relationship (10), thereby allowing each mutant channel to serve as its own control (Fig. 2E and fig. S9). Both conservative $(\mathrm{D} \rightarrow \mathrm{E})$ and harsher $(\mathrm{D} \rightarrow \mathrm{A})$ mutations of Asp805 and Ap808 in L1-2 (corresponding to Asp539 and Asp542 in $\mathrm{Na}_{\mathrm{v}} \mathrm{PaS}$ ) greatly reduced $\Delta_{\mathrm{G}-\mathrm{V}}$, highlighting the critical importance of these residues to Dcla binding. Notably, neither residue is conserved in mammalian $\mathrm{Na}_{\mathrm{v}}$ channels (34), providing a molecular rationale for the insect selectivity of Dcla (10). Mutation of

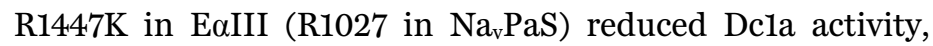
providing support for this unexpected toxin-channel interaction, whereas mutation of His1452 in EaIII (His1032 in $\mathrm{Na}_{\mathrm{v}-}$ $\mathrm{PaS}$ ) had minimal impact. Consistent with the cryo-EM structure (Fig. 2C), mutation of Arg876 (Arg610 in $\mathrm{Na}_{\mathrm{v}} \mathrm{PaS}$ ), one of the uppermost gating charge residues, had minimal impact on Dcla activity, indicating that this residue is not crucial for the Dcla- $\mathrm{Na}_{\mathrm{v}} \mathrm{PaS}$ interaction. Finally, a conservative mutation of Gln1422 (Q1002 in $\mathrm{Na}_{\mathrm{v}} \mathrm{PaS}$ ) on $\mathrm{S}_{\text {III }}$ to Asn greatly reduced toxin activity (Fig. $2 \mathrm{E}$ ), consistent with the interactions observed between this pore-helix residue and residues Lys44 and Phe48 in Dcla (Fig. 2C). Notably, the corresponding residue is Asn in human $\mathrm{Na}_{\mathrm{v}} 1.1-1.8$ and Tyr in $\mathrm{Na}_{\mathrm{v}} 1.9$; again consistent with the insect selectivity of Dcla (10).

In summary, the mutagenesis data provide strong support for the physiological relevance of the complex network of intermolecular interactions observed in the Dcla-Na $\mathrm{NaS}_{\mathrm{P}} \mathrm{Ptruc}-$ ture.

\section{Recognition of TTX}

TTX and STX, both of which have the molecular weight $\sim 300 \mathrm{Da}$, are clearly resolved in the cryo-EM reconstructions (Figs. 3 and 4 and fig. S4). TTX contains one guanidinium, two ether bonds, one oxygen anion, and multiple hydroxyl groups (Fig. 3A and fig. S4A). At lower $\mathrm{pH}$, the oxygen anion is protonated. The map also reveals a density that likely belongs to a coordinated $\mathrm{Na}^{+}$(fig. S4C), which we discuss further below.
TTX blocks the entrance to the selectivity filter (SF) vestibule through an extensive network of electrostatic interactions. The invariant acidic residues on the corresponding locus of the P2 segment in repeats I, II, and IV each form multiple hydrogen bonds or salt bridges with the polar groups of TTX (Fig. 3, B to D). Asp375 and Glu701 in the DEKA motif also directly contribute to TTX binding (Fig. 3C). Three consecutive backbone amides of the residues that demarcate the P2 helix from the preceding SF loop in repeat III simultaneously bind to $\mathrm{ClO}-\mathrm{OH}$ and the oxygen atom of the ether bond between $\mathrm{C} 7$ and C10, while Trp1063 and the carbonyl oxygen of Phe1060 coordinate C9-OH (Fig. 3, B and C).

All of the aforementioned residues are invariant in human $\mathrm{Na}_{\mathrm{v}}$ channels (Fig. 3D). Tyr376 on repeat $\mathrm{I}$ is positioned adjacent to the guanidinium group in TTX, enabling it to make $\pi$-cation interactions with the toxin (Fig. 3, B and C). The corresponding locus is occupied by either Phe or Tyr in TTXsensitive $\mathrm{Na}_{\mathrm{v}}$ channel subtypes, but replaced by Cys or Ser in the TTX-resistant subtypes $\mathrm{Na}_{\mathrm{v}} 1.5, \mathrm{Na}_{\mathrm{v}} 1.8$, and $\mathrm{Na}_{\mathrm{v}} 1.9$ (Fig. 3D). The structure therefore explains why substitution of Cys with Tyr at this position in $\mathrm{Na}_{\mathrm{v}} 1.5$ confers TTX sensitivity (24, 35-37). The position after the invariant Glu on the first helical turn of $\mathrm{P} 2_{\mathrm{I}}$ is occupied by Arg or Lys in TTX-resistant subtypes, whereas an Asn residue occupies this locus in TTXsensitive channels (Fig. 3D). Although this residue is too far away to directly participate in TTX coordination, a basic residue at this site may reduce the local electronegativity and further lower channel affinity for TTX.

\section{Recognition of STX}

The functional groups of STX include the 1,2,3- and 7,8,9- guanidinium groups, the $\mathrm{C} 12$ hydroxyls (C12-OHs), and the 13-carbamoyl group. The distinctive shape of this small molecule allows reliable structural assignment (Fig. 4A and fig. S4, B and D). Polar and charged residues from all four repeats that are positioned at the outer entrance to the SF form extensive interactions with the functional groups of STX (Fig. 4, A and B).

The acidic residues on the first helical turn of the P2 helix in each repeat, which together constitute the outer electronegative ring, provide the primary docking site for STX. The 7,8,9- and 1,2,3-guanidinium groups are respectively bound to the invariant Glu residues on the P2 helix in repeats I and II, while the carbamoyl and the $\mathrm{C} 12-\mathrm{OH}$ are coordinated by polar groups in repeat III and the invariant Asp in repeat IV, respectively. Tyr376 in repeat I contributes to coordination of the toxin through $\pi$-cation interaction with the 1,2,3-guanidinium group of STX (Fig. 4B). The carbonyl oxygen in the carbamoyl group and one adjacent $\mathrm{C} 12-\mathrm{OH}$ are hydrogenbonded to the backbone amide of the invariant Gly (Gly1062 in $\mathrm{Na}_{\mathrm{v}} \mathrm{PaS}$ ) in repeat III. The DEKA-motif residue Glu701 in repeat II forms a hydrogen bond with N7 of STX (Fig. 4B, right). 
All of the STX-coordinating residues in $\mathrm{Na}_{\mathrm{v}} \mathrm{PaS}$, except for Tyr376 and Gln1065, are conserved in mammalian $\mathrm{Na}_{\mathrm{v}}$ channels (Fig. 4C). The corresponding residue for $\mathrm{Na}_{\mathrm{v}} \mathrm{PaS}-\mathrm{Gln} 1065$ is Asp in all human $\mathrm{Na}_{\mathrm{v}}$ subtypes except $\mathrm{Na}_{\mathrm{v}} 1.7$, where this position is occupied by Ile. The $\mathrm{Na}_{\mathrm{v}} \mathrm{PaS}-\mathrm{STX}$ structure provides a molecular basis for the lower affinity of STX for $\mathrm{Na}_{\mathrm{v}} 1.7$ than for $\mathrm{Na}_{\mathrm{v}} 1.4$ (38) as replacement of Gln with a hydrophobic Ile at this locus would lead to a loss of electrostatic interactions with the carbamoyl amine of STX (Fig. 4, B and C).

\section{Molecular mechanism for pore blockade by TTX/STX}

The cryo-EM structures of $\mathrm{Na}_{\mathrm{v}} \mathrm{PaS}$ in complex with TTX or STX reveal the details of their interaction with the channel. However, elucidation of their mechanism of action also requires a molecular understanding of $\mathrm{Na}^{+}$permeation through the SF. Our recent molecular dynamics (MD) simulation of the pore domain of $\mathrm{Na}_{\mathrm{v}} \mathrm{PaS}$ suggests a preferred path involving the acidic residues from repeats I \& II (39) (fig. S10). Examination of the EM map for the $\mathrm{Na}_{\mathrm{v}} \mathrm{PaS}-\mathrm{Dcla}$ complex, which was purified in the presence of $300 \mathrm{mM} \mathrm{NaCl}$, identified a strong density encaged by three acidic residues, Asp375 and Glu701 from the DEKA motif and Glu704 on P2 $2_{\mathrm{II}}$, which is positioned above Glu701 (Fig. 5A). Coordination of this density is nearly identical to that observed in the $2.6 \AA$ reconstruction of the $\mathrm{Na}_{\mathrm{v}} \mathrm{PaS}$-Dcla-TTX complex purified in $150 \mathrm{mM} \mathrm{NaCl}$ (fig. S4C). The stable conformation of the three carboxylate side chains suggests that they may be stabilized by a cation. The density therefore likely belongs to a $\mathrm{Na}^{+}$ion rather than a water molecule. In addition, this site coincides with the energetic minimum observed in the MD simulation of $\mathrm{Na}^{+}$penetration through the $\mathrm{SF}$ of $\mathrm{Na}_{\mathrm{v}} \mathrm{PaS}$. We therefore assigned a $\mathrm{Na}^{+}$ion to this density and refer to this $\mathrm{Na}^{+}$binding site as the "DEE site" (Fig. 5A).

The preference of $\mathrm{Na}^{+}$for the DEE site can be explained by the distinct chemical compositions of the four repeats (Fig. $5 \mathrm{~B}$, left). The invariant Arg on $\mathrm{P}_{\text {II }}$ (Arg696 in $\mathrm{Na}_{\mathrm{V}} \mathrm{PaS}$ ), the Lys in the DEKA motif on repeat III, and a hydrophobic residue on $\mathrm{P} 2_{\text {III }}$ (Leu1064 in $\mathrm{Na}_{\mathrm{v}} \mathrm{PaS}$ and Met in human $\mathrm{Na}_{\mathrm{v}}$ channels) may together repel cations to the DEE site (Fig. 5B and fig. S10). Placement of TTX or STX at the entrance to the SF vestibule preserves the configuration of the DEE site, but completely blocks access of $\mathrm{Na}^{+}$to this site from the extracellular milieu (Fig. 5B).

\section{Summary}

In this study, we report the structures of a eukaryotic $\mathrm{Na}_{\mathrm{v}}$ channel, $\mathrm{Na}_{\mathrm{v}} \mathrm{PaS}$, in complex with three natural toxins. The structures of $\mathrm{Na}_{\mathrm{v}} \mathrm{PaS}$ in complex with the well-characterized neurotoxins TTX and STX provide a molecular explanation for a wealth of functional studies (39-48). It is noteworthy that the molecular weights of TTX and STX are both around $300 \mathrm{Da}$. The clear resolution of these small molecules bound to a $\mathrm{Na}_{\mathrm{v}}$ channel with datasets collected in just a few days showcases the power of cryo-EM, which is likely to play an increasingly important role in structure-aided drug discovery.

The structure of the $\mathrm{Na}_{v} \mathrm{PaS}$-Dcla complex confirmed the important role of $\mathrm{VSD}_{\text {II }}$ in binding this GMT. However, it also revealed that the network of intermolecular interactions is much more complex than previously anticipated, with key interactions between the toxin and both the $\mathrm{S}_{\text {III }}$ pore-domain helix and the extracellular dome above the pore. Thus, one has to apply caution when using isolated $\mathrm{Na}_{\mathrm{v}}$ channel VSDs for drug discovery or for understanding the molecular basis of GMT action. Finally, the recently determined structure of the $\mathrm{EeNa}_{\mathrm{v}} 1.4-\beta 1$ complex revealed that the extracellular dome provides a docking site for $\beta$ subunits (49), which together with the current structure might explain why the sensitivity of $\mathrm{Na}_{\mathrm{v}}$ channels to some GMTs is modulated by the presence of an accessory $\beta$ subunit (50).

\section{Materials and methods}

\section{Purification of $N a_{v} P a S$ in complex with toxins}

Recombinant $\mathrm{Na}_{\mathrm{v}} \mathrm{PaS}$ and Dcla proteins were expressed and purified as reported $(10,34)$. To assemble the complex, Dc1a $(40 \mu \mathrm{M})$ was added to the concentrated $\mathrm{Na}_{\mathrm{v}} \mathrm{PaS}$ solution and incubated at $4^{\circ} \mathrm{C}$ for 0.5 hours before size exclusion chromatography (SEC, Superose ${ }^{\circledR} 6$ 10/300 GL GE Healthcare). For $\mathrm{Na}_{\mathrm{v}} \mathrm{PaS}-\mathrm{Dc1a}$ complexes bound to TTX or STX, TTX $(50 \mu \mathrm{M})$ or STX $(4 \mu \mathrm{M})$ were respectively added to the concentrated $\mathrm{Na}_{\mathrm{v}} \mathrm{PaS}$ solution 15 min before adding Dcla. The peak fractions of size exclusion chromatography were pooled and concentrated to approximately $2 \mathrm{mg} / \mathrm{ml}$. For the sample without TTX or STX, $300 \mathrm{mM} \mathrm{NaCl}$ was used during purification while for the sample with TTX or STX, $150 \mathrm{mM} \mathrm{NaCl}$ was used.

\section{Production of Dc1a analogs}

Plasmids encoding Dcla mutants were generated via PCRbased mutagenesis using a plasmid encoding wild-type Dc1a [pLIC-NSB3; (10)] as template. The DNA sequence of all mutants was confirmed by Sanger sequencing. Peptide concentrations were determined by calculating the area under the RP-HPLC peak (at 214 $\mathrm{nm}$ ) of all analogs, then comparing these to the peak area obtained from a Dcla standard whose concentration had been determined by amino acid analysis.

\section{Cryo-EM data acquisition}

Cryo-EM samples were prepared as described (34). In brief, aliquots $(3.5 \mu \mathrm{l})$ of freshly purified $\mathrm{Na}_{\mathrm{v}} \mathrm{PaS}$ complex were placed on glow-discharged holey carbon grids (Quantifoil $\mathrm{Cu}$ R1.2/1.3), which were blotted for $3.5 \mathrm{~s}$ and flash-frozen in liquid ethane cooled by liquid nitrogen with a Vitrobot Mark IV (Thermo Fisher Scientific Inc.). The grids were subsequently 
transferred to a Titan Krios (Thermo Fisher Scientific Inc.) electron microscopy operating at $300 \mathrm{kV}$ equipped with Cscorrector (Thermo Fisher Scientific Inc.), Gatan K2 Summit detector and GIF Quantum energy filter. A total of 2,764, 3,050 or 4,539 movie stacks, for $\mathrm{Na}_{\mathrm{v}} \mathrm{PaS}$-Dcla complex, TTX or STX-supplemented samples respectively, were automatically collected using AutoEMation (51) with a slit width of $20 \mathrm{eV}$ on the energy filter and a preset defocus range from $-1.8 \mu \mathrm{m}$ to $-1.5 \mu \mathrm{m}$ in super-resolution mode at a nominal magnification of 105,000 X. Each stack was exposed for $5.6 \mathrm{~s}$ with an exposing time of $0.175 \mathrm{~s}$ per frame, resulting in a total of 32 frames per stack. The total dose rate was about $48 \mathrm{e} / \AA^{2}$ for each stack. The stacks were motion corrected with MotionCor2 (52) and binned 2-fold, resulting in a pixel size of $1.091 \AA /$ pixel. Meanwhile, dose weighting was performed (53). The defocus values were estimated with Gctf (54).

\section{Image processing}

The procedure for data processing is summarized in fig. S2. A total of $895,227,1,506,774$, or 1,211,302 particles, for $\mathrm{Na}_{\mathrm{v}} \mathrm{PaS}-$ Dcla complex, TTX or STX-supplemented samples respectively, were automatically picked using RELION (55-58) and Gautomatch (K. Zhang, www.mrc-lmb.cam.ac.uk/kzhang/). After 2D classification, a total of 838,471, 1,042,430 or 447,993 particles were selected for the $\mathrm{Na}_{\mathrm{v}} \mathrm{PaS}-\mathrm{Dcla}$ complex, TTX or STX-supplemented samples and subjected to global angular searching 3D classification with only one class. For each of the last several iterations of the global angular searching 3D classification, a local angular searching 3D classification was performed, during which the particles were classified into 4 classes. A total of non-duplicated $595,020,742,093$ or 378,538 particles were selected from the local angular searching 3D classification for $\mathrm{Na}_{\mathrm{v}} \mathrm{PaS}-\mathrm{Dcla}$ complex, TTX or STXsupplemented samples, respectively. For $\mathrm{Na}_{\mathrm{v}} \mathrm{PaS}-\mathrm{Dcla}$ complex and STX-supplemented samples, the particles were subjected to multi-reference classification to remove bad particles. Then the good particles were subjected to $3 \mathrm{D}$ autorefinement with $255,265,742,093$, or 166,805 particles for $\mathrm{Na}_{\mathrm{v}}$ PaS-Dcla complex, TTX or STX-supplemented samples, respectively. The 3D auto-refinements were further optimized with a larger box size of 320 pixels and local defocus values determined with Gctf. Finally, a local mask was applied during postprocessing to improve the local resolution of pore domain. 2D classification, 3D classification and autorefinement were performed with RELION 2.1. The resolution was estimated with the gold-standard Fourier shell correlation 0.143 criterion (59) with high resolution noise substitution $(60)$.

\section{Model building and structure refinement}

Model building was first carried out based on the $2.9 \AA$ re- construction map of the $\mathrm{Na}_{\mathrm{v}} \mathrm{PaS}-\mathrm{Dcla}$ complex. The structures of $\mathrm{Na}_{\mathrm{v}} \mathrm{PaS}$ and Dcla (PDB accession codes: 5X0M and 2MI5, respectively) were fitted into the EM map by CHIMERA (61). Afterwards, the fitted models were manually adjusted in COOT (62).

In total, 1,380 residues were built with 1,272 side chains assigned for the structure. In addition, 7 sugar and 2 lipid moieties were assigned. The intracellular I-II linker, II-III linker, the N-terminal sequence preceding the NTD, and the C-terminal segment following the CTD were not modeled due to the lack of corresponding densities.

The model of $\mathrm{Na}_{\mathrm{v}} \mathrm{PaS}-\mathrm{Dc1a}$-STX complex was generated using the structure of the $\mathrm{Na}_{\mathrm{v}} \mathrm{PaS}-\mathrm{Dcla}$ complex as the starting model, which was fitted into the $3.2 \AA 3 \mathrm{D}$ reconstruction map. 3D conformer of STX (PubChem CID: 37165) was processed with phenix.elbow application in PHENIX (63) and the resulted structure can be fitted into the map unambiguously in COOT. The docked models and residues were manually adjusted in COOT.

The model of $\mathrm{Na}_{\mathrm{v}} \mathrm{PaS}-\mathrm{Dcla}$-TTX complex was generated using the structure of the $\mathrm{Na}_{\mathrm{v}} \mathrm{PaS}$-Dcla-STX complex as a starting model, which was fitted into the $2.6 \AA 3 \mathrm{D}$ reconstruction map. The 3D structure of TTX (PubChem CID: 11174599) was used to replace STX. Every residue was manually checked in COOT.

Structure refinement was performed using phenix.real_space_refine application in PHENIX in real space with secondary structure and geometry restraints to prevent structure over-fitting. Over-fitting of the overall model was monitored by refining the model in one of the two independent maps from the gold-standard refinement approach and testing the refined model against the other map (64) (fig. S1D). Statistics of the map reconstruction and model refinement can be found in table S1.

\section{Electrophysiology}

Channel mutants were generated using PCR-based mutagenesis with $\mathrm{Na}_{\mathrm{v}} \mathrm{Bg}$ (65) as template, then confirmed by DNA sequencing. Fragments from these mutant clones were excised and cloned back into the original $\mathrm{Na}_{\mathrm{v}} \mathrm{Bg}$ containing plasmid to produce final mutant constructs. The DNA sequence of all constructs was confirmed by Sanger sequencing and cRNA synthesized using T7 polymerase (mMessage mMachine kit, Life Technologies, USA) after linearizing the DNA with NotI restriction enzyme. Xenopus laevis oocytes were injected with cRNA (0.5-4 ng depending on the channel) encoding wild-type or mutant $\mathrm{Na}_{\mathrm{v}} \mathrm{Bg}$ together with the TipE subunit (66) (1:5 molar ratio), then they were incubated at $17^{\circ} \mathrm{C}$ in ND96 solution (in mM: $96 \mathrm{NaCl}, 2 \mathrm{KCl}, 1.8 \mathrm{CaCl}_{2}, 2 \mathrm{MgCl}_{2}$ and 5 HEPES; pH 7.6) supplemented with $5 \mathrm{mM}$ pyruvic acid, $50 \mu \mathrm{g} / \mathrm{mL}$ gentamicin sulfate, and $2.5 \%$ horse serum. Currents 
were recorded 1-3 days after injections using the two-electrode voltage-clamp technique (Axoclamp 900A, Molecular Devices, USA) with a $30 \mu \mathrm{l}$ recording chamber. Microelectrodes were filled with $3 \mathrm{M} \mathrm{KCl}$ and resistances were 0.5-1 M $\Omega$. All experiments were performed at room temperature $\left(\sim 21^{\circ} \mathrm{C}\right)$ in ND96 solution containing $0.1 \%$ fatty-acid free bovine serum albumin to prevent adsorption of peptides to plastic. After addition of peptides to the recording chamber, equilibration between peptide and channel was monitored using weak depolarizations elicited at $5 \mathrm{~s}$ intervals. For all recordings, voltage-activation relationships were recorded in the absence and presence of peptide. To determine conductance-voltage relationships, oocytes were held at $-90 \mathrm{mV}$ and depolarized in 5-mV steps from $-90 \mathrm{mV}$ to $+30 \mathrm{mV}$ for $50 \mathrm{~ms}$. Data were digitized at $20 \mathrm{kHz}$; leak and background conductance were identified by blocking channels with TTX and subtracting background currents. Data analyses were performed using Clampfit 10.5 (Molecular Devices, USA) and Prism 7 (GraphPad Software, USA).

\section{REFERENCES AND NOTES}

1. B. Hille, Ion Channels of Excitable Membranes (Sinauer Associates, ed. 3, 2001), vol. 1, pp. 814.

2. J. Kalia, M. Milescu, J. Salvatierra, J. Wagner, J. K. Klint, G. F. King, B. M. Olivera, F. Bosmans, From foe to friend: Using animal toxins to investigate ion channel function. J. Mol. Biol. 427, 158-175 (2015). doi:10.1016/j.jmb.2014.07.027 Medline

3. J. R. Deuis, Z. Dekan, J. S. Wingerd, J. J. Smith, N. R. Munasinghe, R. F. Bhola, W. L. Imlach, V. Herzig, D. A. Armstrong, K. J. Rosengren, F. Bosmans, S. G. Waxman, S. D. Dib-Hajj, P. Escoubas, M. S. Minett, M. J. Christie, G. F. King, P. F. Alewood, R. J. Lewis, J. N. Wood, I. Vetter, Pharmacological characterisation of the highly Nav1.7 selective spider venom peptide Pn3a. Sci. Rep. 7, 40883 (2017). doi:10.1038/srep40883 Medline

4. J. D. Osteen, V. Herzig, J. Gilchrist, J. J. Emrick, C. Zhang, X. Wang, J. Castro, S. Garcia-Caraballo, L. Grundy, G. Y. Rychkov, A. D. Weyer, Z. Dekan, E. A. B. Undheim, P. Alewood, C. L. Stucky, S. M. Brierley, A. I. Basbaum, F. Bosmans, G. F. King, D. Julius, Selective spider toxins reveal a role for the Nav1.1 channel in mechanical pain. Nature 534, 494-499 (2016). doi:10.1038/nature17976 Medline

5. N. A. Minassian, A. Gibbs, A. Y. Shih, Y. Liu, R. A. Neff, S. W. Sutton, T. Mirzadegan, J. Connor, R. Fellows, M. Husovsky, S. Nelson, M. J. Hunter, M. Flinspach, A. D. Wickenden, Analysis of the structural and molecular basis of voltage-sensitive sodium channel inhibition by the spider toxin huwentoxin-IV ( $\mu$-TRTX-Hh2a). J. Biol. Chem. 288, 22707-22720 (2013). doi:10.1074/jbc.M113.461392 Medline

6. J. K. Murray, J. Ligutti, D. Liu, A. Zou, L. Poppe, H. Li, K. L. Andrews, B. D. Moyer, S. I. McDonough, P. Favreau, R. Stöcklin, L. P. Miranda, Engineering potent and selective analogues of GpTx-1, a tarantula venom peptide antagonist of the $\mathrm{Na}_{\mathrm{v}} \mathrm{l} .7$ sodium channel. J. Med. Chem. 58, 2299-2314 (2015). doi:10.1021/jm501765v Medline

7. S. Cestèle, Y. Qu, J. C. Rogers, H. Rochat, T. Scheuer, W. A. Catterall, Voltage sensortrapping: Enhanced activation of sodium channels by $\beta$-scorpion toxin bound to the S3-S4 loop in domain II. Neuron 21, 919-931 (1998). Medline

8. F. Bosmans, M. F. Martin-Eauclaire, K. J. Swartz, Deconstructing voltage sensor function and pharmacology in sodium channels. Nature 456, 202-208 (2008). doi:10.1038/nature07473 Medline

9. J. Wang, V. Yarov-Yarovoy, R. Kahn, D. Gordon, M. Gurevitz, T. Scheuer, W. A. Catterall, Mapping the receptor site for $\alpha$-scorpion toxins on a $\mathrm{Na}^{+}$channel voltage sensor. Proc. Natl. Acad. Sci. U.S.A. 108, 15426-15431 (2011). doi:10.1073/pnas.1112320108 Medline

10. N. S. Bende, S. Dziemborowicz, M. Mobli, V. Herzig, J. Gilchrist, J. Wagner, G. M. Nicholson, G. F. King, F. Bosmans, A distinct sodium channel voltage-sensor locus determines insect selectivity of the spider toxin Dcla. Nat. Commun. 5, 4350
(2014). doi:10.1038/ncomms5350 Medline

11. C. H. Lau, G. F. King, M. Mobli, Molecular basis of the interaction between gating modifier spider toxins and the voltage sensor of voltage-gated ion channels. Sci. Rep. 6, 34333 (2016). doi:10.1038/srep34333 Medline

12. J. Z. Zhang, V. Yarov-Yarovoy, T. Scheuer, I. Karbat, L. Cohen, D. Gordon, M. Gurevitz, W. A. Catterall, Mapping the interaction site for a $\beta$-scorpion toxin in the pore module of domain III of voltage-gated $\mathrm{Na}^{+}$channels. J. Biol. Chem. 287, 30719-30728 (2012). doi:10.1074/jbc.M112.370742 Medline

13. H. S. Mosher, F. A. Fuhrman, H. D. Buchwald, H. G. Fischer, Tarichatoxintetrodotoxin: A potent neurotoxin. Science 144, 1100-1110 (1964). doi:10.1126/science.144.3622.1100 Medline

14. C. Y. Kao, Tetrodotoxin, saxitoxin and their significance in the study of excitation phenomena. Pharmacol. Rev. 18, 997-1049 (1966). Medline

15. L. M. Durán-Riveroll, A. D. Cembella, Guanidinium toxins and their interactions with voltage-gated sodium ion channels. Mar. Drugs 15, 303 (2017). doi:10.3390/md15100303 Medline

16. J. H. Fleisher, P. J. Killos, C. S. Harrison, Effects of puffer poison on neuromuscular transmission. J. Pharmacol. Exp. Ther. 133, 98-105 (1961). Medline

17. T. Narahashi, J. W. Moore, W. R. Scott, Tetrodotoxin blockage of sodium conductance increase in lobster giant axons. J. Gen. Physiol. 47, 965-974 (1964). doi:10.1085/igp. 47.5.965 Medline

18. W. S. Agnew, S. R. Levinson, J. S. Brabson, M. A. Raftery, Purification of the tetrodotoxin-binding component associated with the voltage-sensitive sodium channel from Electrophorus electricus electroplax membranes. Proc. Natl. Acad. Sci. U.S.A. 75, 2606-2610 (1978). doi:10.1073/pnas.75.6.2606 Medline

19. H. Sommer, K. F. Meyer, Mussel poisoning. Cal. West. Med. 42, 423-426 (1935). Medline

20. J. F. Lawrence, B. Niedzwiadek, C. Menard, Quantitative determination of paralytic shellfish poisoning toxins in shellfish using prechromatographic oxidation and liquid chromatography with fluorescence detection: Collaborative study. J. AOAC Int. 88, 1714-1732 (2005). Medline

21. S. Hagiwara, S. Nakajima, Differences in $\mathrm{Na}$ and $\mathrm{Ca}$ spikes as examined by application of tetrodotoxin, procaine, and manganese ions. J. Gen. Physiol. 49, 793-806 (1966). doi:10.1085/jgp.49.4.793 Medline

22. J. K. Reed, M. A. Raftery, Properties of the tetrodotoxin binding component in plasma membranes isolated from Electrophorus electricus. Biochemistry 15, 944953 (1976). doi:10.1021/bi00650a002 Medline

23. T. Clairfeuille, H. Xu, C. M. Koth, J. Payandeh, Voltage-gated sodium channels viewed through a structural biology lens. Curr. Opin. Struct. Biol. 45, 74-84 (2017). doi:10.1016/j.sbi.2016.11.022 Medline

24. J. Satin, J. W. Kyle, M. Chen, P. Bell, L. L. Cribbs, H. A. Fozzard, R. B. Rogart, A mutant of TTX-resistant cardiac sodium channels with TTX-sensitive properties. Science 256, 1202-1205 (1992). doi:10.1126/science.256.5060.1202 Medline

25. N. T. Blair, B. P. Bean, Roles of tetrodotoxin (TTX)-sensitive Na ${ }^{+}$current, TTXresistant $\mathrm{Na}^{+}$current, and $\mathrm{Ca}^{2+}$ current in the action potentials of nociceptive sensory neurons. J. Neurosci. 22, 10277-10290 (2002). doi:10.1523/JNEUROSCI.22-23-10277.2002 Medline

26. S. Cestèle, W. A. Catterall, Molecular mechanisms of neurotoxin action on voltagegated sodium channels. Biochimie 82, 883-892 (2000). doi:10.1016/S03009084(00)01174-3 Medline

27. G. M. Lipkind, H. A. Fozzard, A structural model of the tetrodotoxin and saxitoxin binding site of the $\mathrm{Na}^{+}$channel. Biophys. J. 66, 1-13 (1994). doi:10.1016/S00063495(94)80746-5 Medline

28. B. Hille, The receptor for tetrodotoxin and saxitoxin. A structural hypothesis Biophys. J. 15, 615-619 (1975). doi:10.1016/S0006-3495(75)85842-5 Medline

29. A. P. Thottumkara, W. H. Parsons, J. Du Bois, Saxitoxin. Angew. Chem. Int. Ed. 53 , 5760-5784 (2014). doi:10.1002/anie.201308235 Medline

30. J. Payandeh, T. Scheuer, N. Zheng, W. A. Catterall, The crystal structure of a voltage-gated sodium channel. Nature 475, 353-358 (2011). doi:10.1038/nature10238 Medline

31. X. Zhang, W. Ren, P. DeCaen, C. Yan, X. Tao, L. Tang, J. Wang, K. Hasegawa, T. Kumasaka, J. He, J. Wang, D. E. Clapham, N. Yan, Crystal structure of an orthologue of the NaChBac voltage-gated sodium channel. Nature 486, 130-134 (2012). doi:10.1038/nature11054 Medline

32. E. C. McCusker, C. Bagnéris, C. E. Naylor, A. R. Cole, N. D’Avanzo, C. G. Nichols, B. 
A. Wallace, Structure of a bacterial voltage-gated sodium channel pore reveals mechanisms of opening and closing. Nat. Commun. 3, 1102 (2012). doi:10.1038/ncomms2077 Medline

33. D. Ren, B. Navarro, H. Xu, L. Yue, Q. Shi, D. E. Clapham, A prokaryotic voltage-gated sodium channel. Science 294, 2372-2375 (2001). doi:10.1126/science.1065635 Medline

34. H. Shen, Q. Zhou, X. Pan, Z. Li, J. Wu, N. Yan, Structure of a eukaryotic voltagegated sodium channel at near-atomic resolution. Science 355, eaal4326 (2017). doi:10.1126/science.aal4326 Medline

35. D. A. Dougherty, Cation-m interactions in chemistry and biology: A new view of benzene, Phe, Tyr, and Trp. Science 271, 163-168 (1996). doi:10.1126/science.271.5246.163 Medline

36. S. H. Heinemann, H. Terlau, K. Imoto, Molecular basis for pharmacological differences between brain and cardiac sodium channels. Pflugers Arch. 422, 9092 (1992). doi:10.1007/BF00381519 Medline

37. P. H. Backx, D. T. Yue, J. H. Lawrence, E. Marban, G. F. Tomaselli, Molecular localization of an ion-binding site within the pore of mammalian sodium channels. Science 257, 248-251 (1992). doi:10.1126/science.1321496 Medline

38. J. R. Walker, P. A. Novick, W. H. Parsons, M. McGregor, J. Zablocki, V. S. Pande, J. Du Bois, Marked difference in saxitoxin and tetrodotoxin affinity for the human nociceptive voltage-gated sodium channel (Nav1.7). Proc. Natl. Acad. Sci. U.S.A. 109, 18102-18107 (2012). doi:10.1073/pnas.1206952109 Medline

39. J. Zhang, W. Mao, Y. Ren, R. N. Sun, N. Yan, H. Gong, Simulating the ion permeation and ion selection for a eukaryotic voltage-gated sodium channel NavPaS. Protein Cell 9, 580-585 (2018). Medline

40. M. Noda, H. Suzuki, S. Numa, W. Stühmer, A single point mutation confers tetrodotoxin and saxitoxin insensitivity on the sodium channel II. FEBS Lett. 259, 213-216 (1989). doi:10.1016/0014-5793(89)81531-5 Medline

41. H. Terlau, S. H. Heinemann, W. Stühmer, M. Pusch, F. Conti, K. Imoto, S. Numa, Mapping the site of block by tetrodotoxin and saxitoxin of sodium channel II. FEBS Lett. 293, 93-96 (1991). doi:10.1016/0014-5793(91)81159-6 Medline

42. K. J. Kontis, A. L. Goldin, Site-directed mutagenesis of the putative pore region of the rat IIA sodium channel. Mol. Pharmacol. 43, 635-644 (1993). Medline

43. H. Nakayama, Y. Hatanaka, E. Yoshida, K. Oka, M. Takanohashi, Y. Amano, Y. Kanaoka, Photolabeled sites with a tetrodotoxin derivative in the domain III and IV of the electroplax sodium channel. Biochem. Biophys. Res. Commun. 184, $900-$ 907 (1992). doi:10.1016/0006-291X(92)90676-C Medline

44. J. L. Penzotti, H. A. Fozzard, G. M. Lipkind, S. C. Dudley Jr., Differences in saxitoxin and tetrodotoxin binding revealed by mutagenesis of the $\mathrm{Na}^{+}$channel outer vestibule. Biophys. J. 75, 2647-2657 (1998). doi:10.1016/S00063495(98)77710-0 Medline

45. J. L. Penzotti, G. Lipkind, H. A. Fozzard, S. C. Dudley Jr., Specific neosaxitoxin interactions with the $\mathrm{Na}^{+}$channel outer vestibule determined by mutant cycle analysis. Biophys. J. 80, 698-706 (2001). doi:10.1016/S0006-3495(01)76049-3 Medline

46. G. Choudhary, L. Shang, X. Li, S. C. Dudley Jr., Energetic localization of saxitoxin in its channel binding site. Biophys. J. 83, 912-919 (2002). doi:10.1016/S00063495(02)75217-X Medline

47. G. Choudhary, M. Yotsu-Yamashita, L. Shang, T. Yasumoto, S. C. Dudley Jr., Interactions of the C-11 hydroxyl of tetrodotoxin with the sodium channel outer vestibule. Biophys. J. 84, 287-294 (2003). doi:10.1016/S0006-3495(03)748498 Medline

48. E. Carbonneau, K. Vijayaragavan, M. Chahine, A tryptophan residue (W736) in the amino-terminus of the P-segment of domain II is involved in pore formation in Nav1.4 voltage-gated sodium channels. Pflugers Arch. 445, 18-24 (2002). doi:10.1007/s00424-002-0887-9 Medline

49. Z. Yan, Q. Zhou, L. Wang, J. Wu, Y. Zhao, G. Huang, W. Peng, H. Shen, J. Lei, N. Yan, Structure of the Nav1.4- $\beta 1$ complex from electric eel. Cell 170, 470-482.el1 (2017). doi:10.1016/j.cell.2017.06.039 Medline

50. J. Gilchrist, S. Das, F. Van Petegem, F. Bosmans, Crystallographic insights into sodium-channel modulation by the $\beta 4$ subunit. Proc. Natl. Acad. Sci. U.S.A. 110, E5016-E5024 (2013). doi:10.1073/pnas.1314557110 Medline

51. J. Lei, J. Frank, Automated acquisition of cryo-electron micrographs for single particle reconstruction on an FEI Tecnai electron microscope. J. Struct. Biol. 150, 69-80 (2005). doi:10.1016/j.jsb.2005.01.002 Medline
52. S. O. Zheng, E. Palovcak, J.-P. Armache, K. A. Verba, Y. Cheng, D. A. Agard, MotionCor2: Anisotropic correction of beam-induced motion for improved cryoelectron microscopy. Nat. Methods 14, 331-332 (2017). doi:10.1038/nmeth.4193 Medline

53. T. Grant, N. Grigorieff, Measuring the optimal exposure for single particle cryo-EM using a $2.6 \AA$ reconstruction of rotavirus VP6. elife 4, e06980 (2015). doi:10.7554/eLife.06980 Medline

54. K. Zhang, Gctf: Real-time CTF determination and correction. J. Struct. Biol. 193, 112 (2016). doi:10.1016/j.jsb.2015.11.003 Medline

55. S. H. Scheres, A Bayesian view on cryo-EM structure determination. J. Mol. Biol. 415, 406-418 (2012). doi:10.1016/j.jmb.2011.11.010 Medline

56. S. H. Scheres, RELION: Implementation of a Bayesian approach to cryo-EM structure determination. J. Struct. Biol. 180, 519-530 (2012). doi:10.1016/j.jsb.2012.09.006 Medline

57. S. H. Scheres, Semi-automated selection of cryo-EM particles in RELION-1.3. J. Struct. Biol. 189, 114-122 (2015). doi:10.1016/i.jsb.2014.11.010 Medline

58. D. Kimanius, B. O. Forsberg, S. H. Scheres, E. Lindahl, Accelerated cryo-EM structure determination with parallelisation using GPUs in RELION-2. eLife 5, e18722 (2016). doi:10.7554/eLife.18722 Medline

59. P. B. Rosenthal, R. Henderson, Optimal determination of particle orientation, absolute hand, and contrast loss in single-particle electron cryomicroscopy. J. Mol. Biol. 333, 721-745 (2003). doi:10.1016/j.jmb.2003.07.013 Medline

60. S. Chen, G. McMullan, A. R. Faruqi, G. N. Murshudov, J. M. Short, S. H. W. Scheres, R. Henderson, High-resolution noise substitution to measure overfitting and validate resolution in $3 \mathrm{D}$ structure determination by single particle electron cryomicroscopy. Ultramicroscopy 135, 24-35 (2013) doi:10.1016/j.ultramic.2013.06.004 Medline

61. E. F. Pettersen, T. D. Goddard, C. C. Huang, G. S. Couch, D. M. Greenblatt, E. C. Meng, T. E. Ferrin, UCSF Chimera-A visualization system for exploratory research and analysis. J. Comput. Chem. 25, 1605-1612 (2004). doi:10.1002/jcc.20084 Medline

62. P. Emsley, B. Lohkamp, W. G. Scott, K. Cowtan, Features and development of Coot. Acta Crystallogr. D Biol. Crystallogr. 66, 486-501 (2010). doi:10.1107/S0907444910007493 Medline

63. P. D. Adams, P. V. Afonine, G. Bunkóczi, V. B. Chen, I. W. Davis, N. Echols, J. J. Headd, L.-W. Hung, G. J. Kapral, R. W. Grosse-Kunstleve, A. J. McCoy, N. W. Moriarty, R. Oeffner, R. J. Read, D. C. Richardson, J. S. Richardson, T. C. Terwilliger, P. H. Zwart, PHENIX: A comprehensive Python-based system for macromolecular structure solution. Acta Crystallogr. D Biol. Crystallogr. 66, 213221 (2010). doi:10.1107/S0907444909052925 Medline

64. A. Amunts, A. Brown, X. C. Bai, J. L. Llácer, T. Hussain, P. Emsley, F. Long, G. Murshudov, S. H. W. Scheres, V. Ramakrishnan, Structure of the yeast mitochondrial large ribosomal subunit. Science 343, 1485-1489 (2014). doi:10.1126/science.1249410 Medline

65. K. Dong, A single amino acid change in the para sodium channel protein is associated with knockdown-resistance (kdr) to pyrethroid insecticides in German cockroach. Insect Biochem. Mol. Biol. 27, 93-100 (1997). doi:10.1016/S09651748(96)00082-3 Medline

66. G. Feng, P. Deák, M. Chopra, L. M. Hall, Cloning and functional analysis of TipE, a novel membrane protein that enhances Drosophila para sodium channel function. Cell 82, 1001-1011 (1995). doi:10.1016/0092-8674(95)90279-1 Medline

67. W. L. DeLano, The PyMOL Molecular Graphics System (2002); www.pymol.org.

\section{ACKNOWLEDGMENTS}

We thank Xiaomin Li (Tsinghua University) for technical support during EM image acquisition. We thank Ke Dong (Michigan State University) for sharing BgNav1 ( $\mathrm{Nav} \mathrm{Bg}$ ) and TipE constructs. Funding: This work was funded by the National Key Basic Research (973) Program (2015CB910101 to N.Y.) and the National Key R\&D Program (2016YFA0500402 to N.Y. and 2016YFA0501100 to J.L.) from Ministry of Science and Technology of China, the National Natural Science Foundation of China (projects 31621092, 31630017, and 31611130036 to N. Y.), the Australian Research Council (DP160104411), and the Australian National Health \& Medical Research Council (Principal Research Fellowship and Program Grant APP1072113 to G.F.K.). We thank the Tsinghua University Branch of China National Center for Protein Sciences (Beijing) for providing the cryo-EM facility 
support. We thank the computational facility support on the cluster of BioComputing Platform (Tsinghua University Branch of China National Center for Protein Sciences Beijing) and the "Explorer 100" cluster system of Tsinghua National Laboratory for Information Science and Technology. N.Y. is supported by the Shirley M. Tilghman endowed professorship from Princeton University.

Ethics statement: This study was carried out in accordance with the recommendations in the Australian code of practice for the care and use of animals for scientific purposes (8th Ed., 2013). The protocol for Xenopus laevis studies was approved by the Animal Ethics Committee of The University of Queensland (approval number QBI/059/13/ARC/NHMRC). Surgeries for harvesting Xenopus laevis oocytes with recovery end-point were performed under anesthesia (animals exposed to tank filled with $1.3 \mathrm{mg} / \mathrm{ml}$ of MS-222), with a minimum of three months between surgeries. Author contributions: N.Y., G.F.K., and Q.Z. conceived the project. H.S., Q.Z., Z.L., J.Y., X.P., J.W., B.C., J.J.S., Y.K.Y.C., and J.L. performed the experiments. All authors contributed to data analysis. N.Y. G.F.K, Q.Z., and H.S. wrote the manuscript. Competing interests: The authors declare no competing interests. Data and materials availability: The atomic coordinates for $\mathrm{NavPaS}$-Dcla complex, NavPaS-Dcla-TTX complex, and $\mathrm{Na}_{\mathrm{v}} \mathrm{PaS}$-Dcla-STX complex have been deposited in the Protein Data Bank (http://www.rcsb.org) with the accession code 6A90, 6A95 and 6A91

respectively. The EM maps have been deposited in EMDB

(https://www.ebi.ac.uk/pdbe/emdb/) with accession code EMD-6995, EMD-

6997 and EMD-6996 respectively.

\section{SUPPLEMENTARY MATERIALS}

www.sciencemag.org/cgi/content/full/science.aau2596/DC1

Figs. S1 to S10

Table S1

References

22 May 2018; accepted 17 July 2018

Published online 26 July 2018

10.1126/science.aau2596 
A
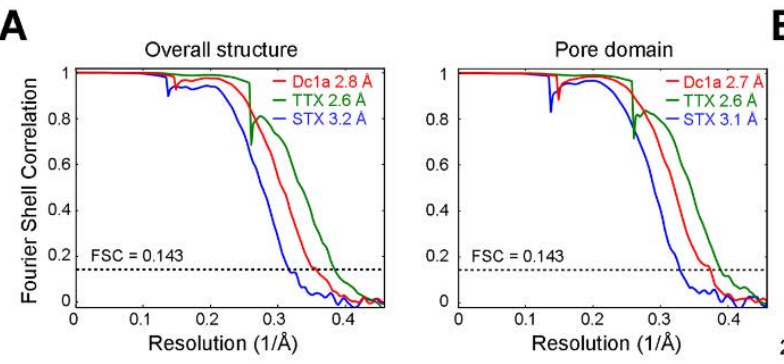

B

C
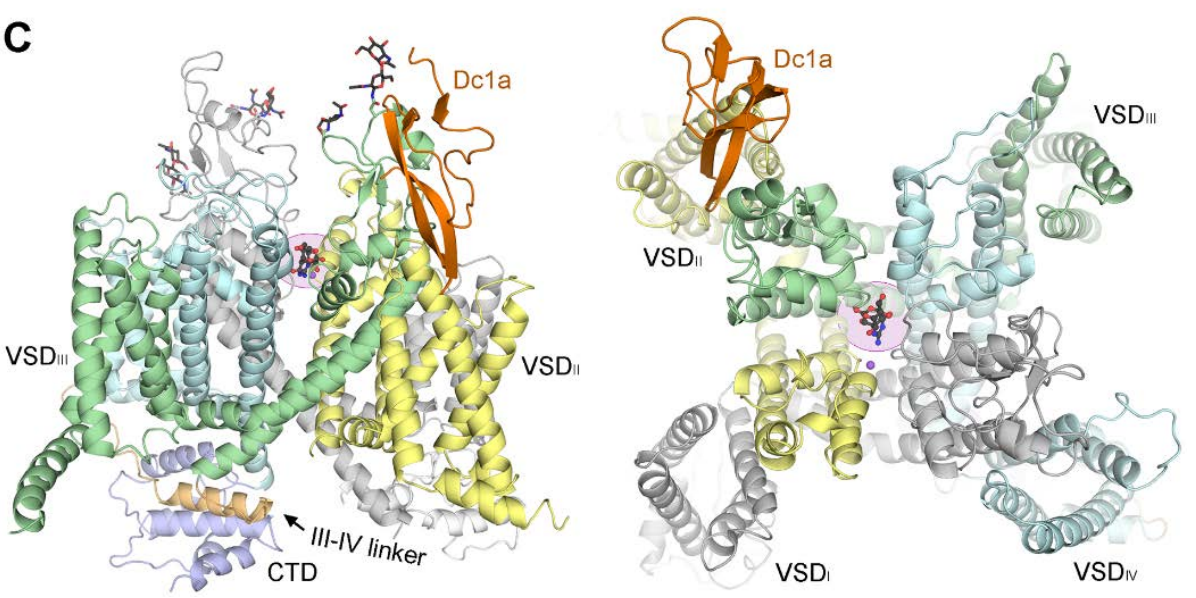

Fig. 1. Structures of the complex between $\mathrm{Na}_{\mathrm{v}} \mathrm{PaS}$ and the peptide toxin Dcla with or without TTX/STX. (A) Gold-standard Fourier shell correlation (FSC) curves for the 3D EM reconstructions of the $\mathrm{Na}_{\mathrm{v}} \mathrm{PaS}-\mathrm{Dcl}$ la complex in the absence or presence of TTX or STX. Left: FSC curves for the overall structures. Right: FSC curves for the pore domains that were masked during post-processing. (B) Local resolution map of the NavPaS-Dcla-TTX complex. The map was estimated with RELION 2.0 and generated in Chimera. (C) Overall structure of the $\mathrm{Na}_{\mathrm{v}} \mathrm{PaS}$-Dcla-TTX complex. Side view and top view are shown. Since the three overall structures are nearly identical, only one is shown as a representative. The four repeats in $\mathrm{Na}_{\mathrm{v}} \mathrm{PaS}$ are shown in different colors and Dcla is colored orange. The sugar moieties are shown as black sticks. TTX, shown as black ball-and-sticks, is highlighted by the pink shade. The putative $\mathrm{Na}^{+}$ion is shown as purple sphere. All structure figures were prepared with PyMol (67). 

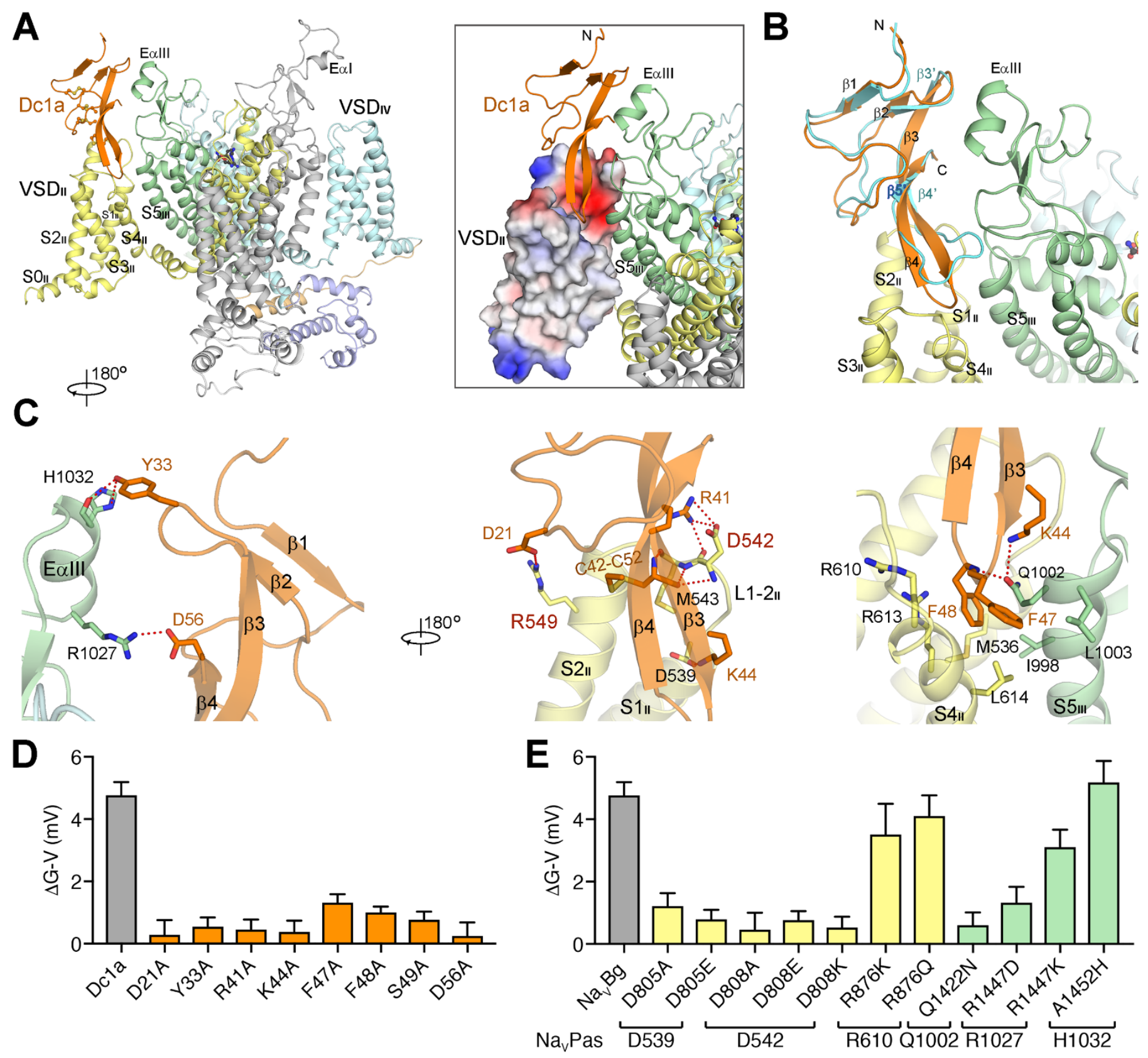
Fig. 2. The interaction between Dcla and $\mathrm{Na}_{\mathrm{v}} \mathrm{PaS}$. (A) Dcla inserts into the extracellular cavity between VSD II and the pore elements of repeat III. The four disulfide bonds in Dcla are shown as ball and sticks. Ealll: The extracellular $\alpha$ helix in Repeat III. Inset: VSD $D_{\|}$is shown as surface electrostatic potential calculated in PyMol. (B) The conformational changes of Dcla upon binding to $\mathrm{Na}_{\mathrm{v}} \mathrm{PaS}$. The NMR-determined structure of free Dcla (cyan) contains five short $\beta$-strands, with $\beta 4$ and $\beta 5$ connected by a flexible linker. When binding to $\mathrm{Nav} P a S$, the segments containing $\beta 3-\beta 5$ (labeled as $\beta 3$ '- $\beta 5$ ' to be distinguished from those in the complex structure) become rigidified to form an elongated $\beta$ hairpin. (C) Specific interactions between Dcla and $\mathrm{Na}_{\mathrm{v}} \mathrm{PaS}$. Electrostatic interactions are shown as red dashed lines. The three panels illustrate the contacts from top to bottom. Left: Interactions between Dcla and the extracellular segments above the pore domain in Repeat III of $\mathrm{Na}_{\mathrm{v}} \mathrm{PaS}$. Middle: Interactions between Dcla and the L1-2 „I loop (the loop that connects the S1 and S2 segments in $V_{S D_{\|}}$). Asp542 and Arg549, which are not conserved in mammalian $\mathrm{Na}_{v}$ channels, are highlighted with red labels. Right: Interactions of Dcla with S4 ${ }_{\|}$and S5 III. (D and E) Structureguided mutagenesis characterizations corroborate the structural observations. (D) Shift in G-V curve $\left(\Delta_{\mathrm{G}-\mathrm{V}}\right)$ for $\mathrm{Na} \mathrm{v}_{\mathrm{V}} \mathrm{Bg}$ induced by wild-type $(\mathrm{WT})$ and mutant Dcla peptides $(1 \mu \mathrm{M})$. WT Dcla is shown in grey while mutants are colored orange $(n=5-7)$. (E) Shift in G-V curve $\left(\Delta_{\mathrm{G}-\mathrm{v}}\right)$ for WT and mutant $\mathrm{Na}_{\mathrm{v}} \mathrm{Bg}$ channels induced by WT Dcla $(1 \mu \mathrm{M})$. Mutants are labeled according to the sequence of WT $\mathrm{Na}_{\mathrm{v}} \mathrm{Bg}$, with corresponding $\mathrm{Na}_{\mathrm{v}} \mathrm{PaS}$ numbering below. WT channel is shown in grey, while residues located in VSD ${ }_{\|}$and S5-S6 ${ }_{\| \prime}$ are colored yellow and green, respectively $(n=5-6)$. All data are mean \pm s.e.m. Please refer to figs. S6 to S9 for experimental details. 


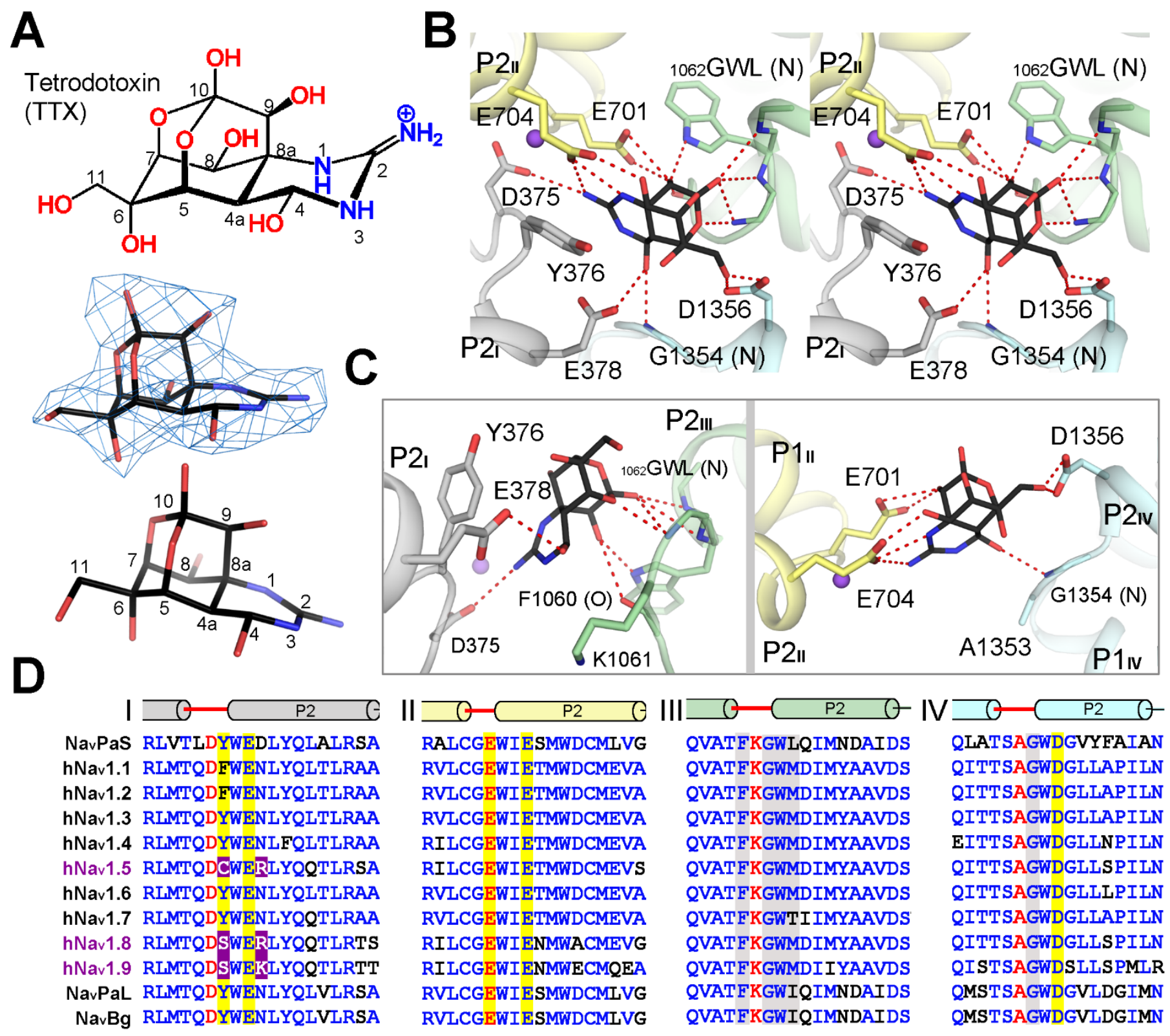

Fig. 3. Specific interactions between $\mathrm{Na}_{\mathrm{v}} \mathrm{PaS}$ and TTX. (A) Structure of TTX. Top: The chemical structure of TTX. Middle: The density for TTX, shown as blue mesh, is contoured at $10 \sigma$. Bottom: The resolved 3D structure of TTX bound to $\mathrm{Na}_{\mathrm{v}} \mathrm{PaS}$. (B) TTX is specifically coordinated by acidic residues and backbone amides at the outer vestibule of the SF. A stereo view from the extracellular side is shown. The putative $\mathrm{Na}^{+}$ion is shown as purple sphere. (C) The detailed coordination of TTX by residues from the diagonal repeats shown in side views. (D) Sequence alignment of the SF elements and P2 helices in the four channel repeats. The panel is adapted from the reported sequence alignment (34). The residues whose side chains are involved in TTX coordination via polar interactions are shaded yellow. The residues whose backbone amides bind to the oxygen anion are shaded grey. In the TTXresistant $\mathrm{Na}_{v}$ subtypes, the equivalent of Tyr376, which appears to form $\pi$-cation interaction with the 1,2,3-guanidinium of TTX, is Cys ( $\left.\mathrm{Na}_{v} 1.5\right)$ or Ser ( $\mathrm{Na}_{v} 1.8$ and $\left.\mathrm{Na}_{v} 1.9\right)$. 
A

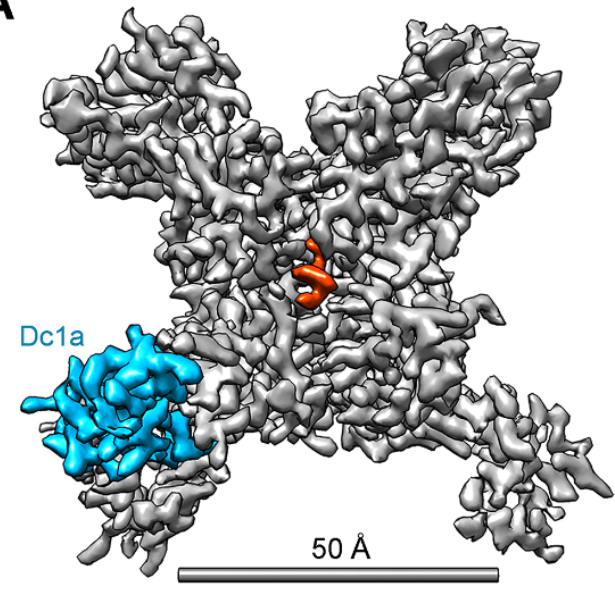

B

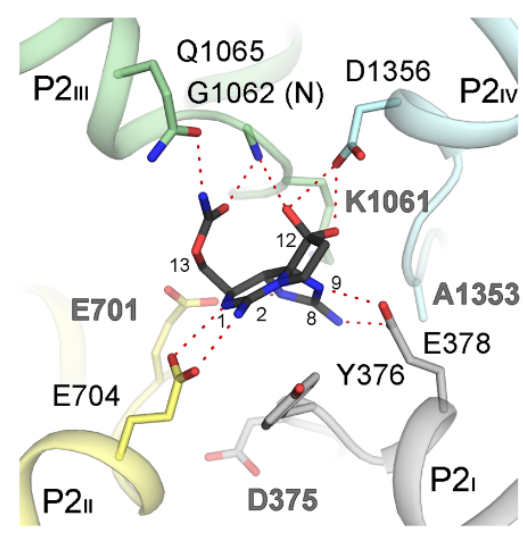

C<smiles>NC(=O)OC[C@H]1N=C(N)N2CCC(O)(O)C[C@]23NC(N)=N[C@H]13</smiles>

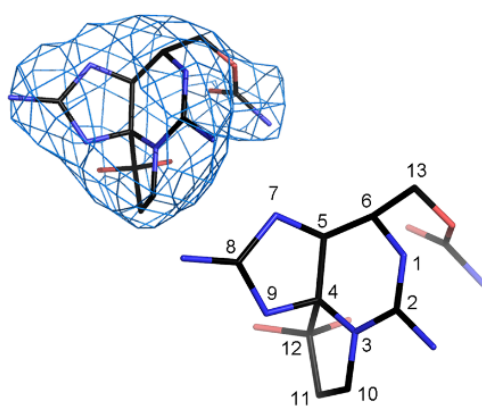
NavPaS RLVTLDYWEDLYQLALRSA hNav1.1 RLMTQDFWENLYQLTLRAA hNav1.2 RLMTODFWENLYOLTLRAA hNav1.3 RLMTQDYWENLYQLTLRAA $\begin{array}{ll}\text { hNav1.3 } & \text { RLMTQDYWENLYQLTLRAA } \\ \text { hNav1.4 RLMTODYWENLFOLTLRAA }\end{array}$ hNav1.5 RLMTQDCWERLYQQTLRSA hNav1.6 RLMTQDYWENLYQLTLRAA hNav1.7 RLMTQDYWENLYQQTLRAA hNav1.8 RLMTQDSWERLYQQTLRTS hNav1.9 RLMTQDSWEKLYQQTLRTT NavPaL RLMTQDYWENLYQLVLRSA NavBg RLMTQDYWENLYQLVLRSA
II $\mathrm{O}-\mathrm{P2}$

NavPaS RALCGEWIESMWDCMLVG hNav1.1 RVLCGEWIETMWDCMEVA hNav1.2 RVLCGEWIETMWDCMEVA hNav1.3 RVLCGEWIETMWDCMEVA hNav1.4 RILCGEWIETMWDCMEVA hNav1.5 RILCGEWIETMWDCMEVS hNav1.6 RVLCGEWIETMWDCMEVA hNav1.7 RVLCGEWIETMWDCMEVA hNav1.8 RILCGEWIENMWACMEVG hNav1.9 RILCGEWIENMWECMQEA NavPaL RVLCGEWIESMWDCMLVG NavBg RVLCGEWIESMWDCMLVG
III $O P 2 \quad Q$ QVATFKGWLQIMNDAIDS QVATFKGWMDIMYAAVDS QVATFKGWMDIMYAAVDS QVATFKGWMDIMYAAVDS QVATFKGWMDIMYAAVDS QVATFKGWMDIMYAAVDS QVATFKGWMDIMYAAVDS OVATFKGWTIIMYAAVDS Q QVATFKGWMDIIYAAVD QVATFKGWIQIMNDAIDS QVATFKGWIQIMNDAIDS

IV $\rightarrow \longrightarrow P 2$ QLATSAGWDGVYFAIAN QITTSAGWDGLLAPILN QITTSAGWDGLLAPILN QITTSAGWDGLLAPILN EITTSAGWDGLLNPILN QITTSAGWDGLLSPILN QITTSAGWDGLLLPILN QITTSAGWDGLLAPILN QITTSAGWDGLLSPILN OISTSAGWDSLLSPMLR OMSTSAGWDGVLDGIMN QMSTSAGWDGVLDGIMN

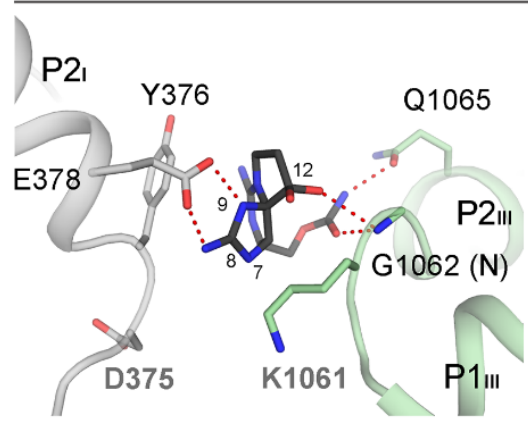

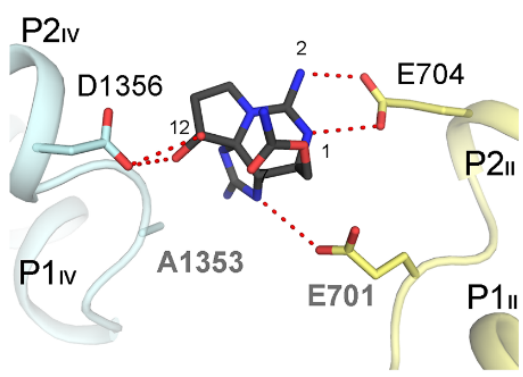

Fig. 4. Specific interactions between $\mathrm{Na}_{\mathrm{v}} \mathrm{PaS}$ and STX. (A) STX is well resolved in the 3.1 A-resolution EM reconstruction of the central domain of $\mathrm{Na}_{\mathrm{v}} \mathrm{PaS}$. Left: An extracellular view of the overall EM map. The densities corresponding to STX and Dcla are colored red and cyan, respectively. Right: Chemical structure (top) and 3D structure (bottom) of the $\mathrm{Na}_{\vee} \mathrm{PaS}$-bound STX. Shown in the middle is the density (blue mesh) for the bound STX at 5 $\sigma$. (B) STX is specifically coordinated by charged and polar residues from the four repeats at the outer vestibule of the SF. Left: STX tightly blocks the entrance to the SF. An extracellular view is shown. Middle and right: Side views of the coordination of STX by residues from the diagonal repeats. (C) Sequence alignment of the SF elements and P2 helices in the four repeats. Similar to Fig. 3D, the residues that participate in STX coordination via polar interactions are shaded yellow. Tyr376, which forms a m-cation interaction with the 1,2,3guanidinium of STX, is shaded grey. The locus corresponding to NavPaS-Q1065 is Ile in human $\mathrm{Na}_{\mathrm{v}} 1.7$, which has a much lower affinity for STX than other subtypes of human $\mathrm{Na}_{\mathrm{v}}$ channels in which this locus is occupied by Asp. 
A
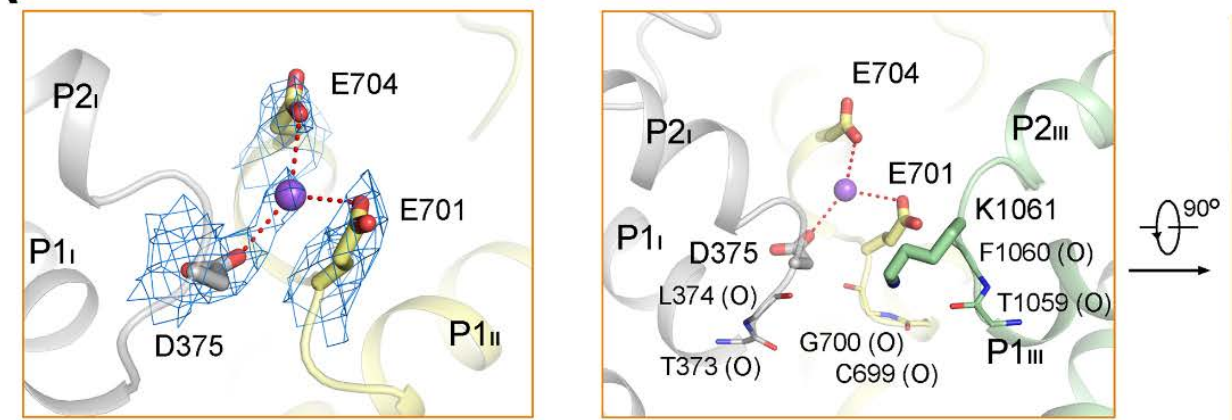

B
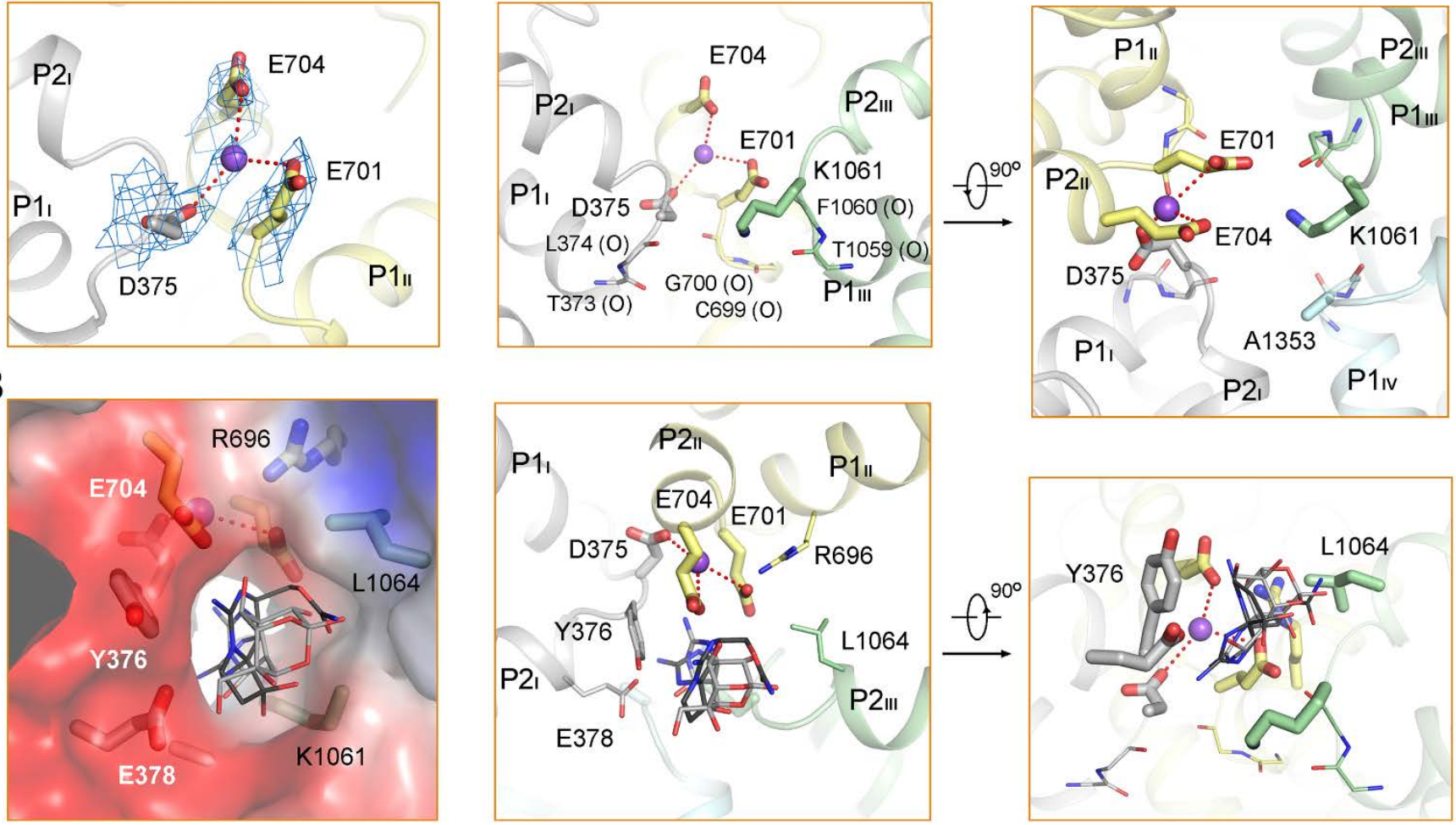

Fig. 5. Molecular mechanism for pore blockade by TTX/STX. (A) A potential $\mathrm{Na}^{+}$binding site within SF. The carboxylate groups of DE and an invariant Glu on P2 „I together constitute a potential $\mathrm{Na}^{+}$binding site (designated the DEE site). Left: A density surrounded by three carboxylate groups may belong to a bound $\mathrm{Na}^{+}$ion in the structure of $\mathrm{Na}_{v} \mathrm{PaS}-\mathrm{Dcla}$, which was purified in the presence of $300 \mathrm{mM} \mathrm{NaCl}$. A similar density is observed in the EM map for $\mathrm{Na}_{\mathrm{v}} \mathrm{PaS}$-Dcla-TTX. Please refer to fig. S4C. Middle and right: Asymmetric coordination of the $\mathrm{Na}^{+}$ion within the SF vestibule. Side and top views of the SF vestibule are shown. Repeat IV is omitted in the side view for visual clarity. The carbonyl oxygens that constitute the potential inner site for $\mathrm{Na}^{+}$within the SF are shown as thin sticks. The structural observation is consistent with a recent MD simulation analysis of the $\mathrm{Na}^{+}$permeation path (39). See fig. S10 for details. (B) TTX/STX completely blocks access of $\mathrm{Na}^{+}$to the DEE site from the extracellular side. Left: The asymmetric chemical composition of the SF outer vestibule determines the permeation path for $\mathrm{Na}^{+}$. Shown here is a semi-transparent presentation of the electrostatic surface potential of the entrance to the SF viewed from the extracellular side. The residues that give rise to the surface feature are shown in sticks. TTX and STX are shown as silver and black sticks, respectively. Middle and right: The relative position of TTX/STX with respect to the bound $\mathrm{Na}^{+}$ion. Placement of TTX/STX at the outer mouth to $\mathrm{SF}$ prevents the access of $\mathrm{Na}^{+}$to the DEE site from the extracellular side. 